\title{
Serum Long Intergenic Non-Coding Ribonucleic Acid LINC00152 as a Potential Predictor of Hepatocellular Carcinoma in Egyptian Patients
}

\author{
Ehsan Abdelrahman ${ }^{1}$,Ahmed Abd El Aal ${ }^{1}$,Mona Sobhy ${ }^{1}$,Ayman Shamsya ${ }^{2}$,Yasmin \\ Zanet $^{1}$,Essam El-Din S Bedewy ${ }^{3}$ \\ ${ }^{1}$ Department of Medical Biochemistry, Faculty of Medicine, Alexandria University, Egypt \\ ${ }^{2}$ Department of Internal Medicine, Faculty of Medicine, Alexandria University, Egypt \\ ${ }^{3}$ Department of Tropical Medicine, Faculty of Medicine, Alexandria University, Egypt
}

Corresponding Author

Essam Bedewy

Mobile:

$+201100771111$

E-mail: essambedewyclinic@g mail.com

Key words: Liver cirrhosis, Hepatocellular carcinoma, LINC00152
Background and study aim: HCC diagnosis is mostly dependent on imaging studies as well as laboratory tests. The aim of this study is to evaluate possible significance of circulating Linc00152 level as a potential diagnostic marker for HCC diagnosis among Egyptian patients.

Patients and Methods: This Cohort (Prospective observational) study was conducted on 60 patients, who were further divided into three groups; 30 patients with cirrhosis and HCC on top (group I), this group was further subdivided into: 15 HCC patients (stage C and D) according to Barcelona-Clinic Liver Cancer (BCLC) staging system (group IA) and $15 \mathrm{HCC}$ patients (stage A and $\mathrm{B}$ ) according to BCLC staging system (group IB); 15 cirrhotic patients without HCC (group II), lastly 15 healthy subjects with matched age and sex as a control Group (group III). All were subjected to history taking, clinical evaluation, basic liver functions, AFP, ultrasound abdomen followed by Triphasic CT abdomen to document presence of HCC and Linc00152 level assessment

Results: Circulating Linc00152 was elevated in-group I compared to two other groups. Serum Linc00152 yielded showed $90 \%$ sensitivity and $66.67 \%$ specificity in discriminating HCC from cirrhosis, compared to AFP that showed $63.33 \%$ sensitivity and $60 \%$ specificity, Combination of Linc00152 and AFP might possess a higher ability to discriminate between HCC and cirrhosis rather than without combination.

Conclusion: HCC is clearly accompanied by over expression of serum Linc00152. This study suggested that Linc00152 may be promising diagnostic markers for early HCC, also for cirrhosis detection.

\section{INTRODUCTION}

HCC diagnosis is mostly dependent on imaging studies as well as laboratory tests. Characteristic pattern in imaging dynamic techniques (triphasic CT scan, magnetic resonance imaging, contrast-enhanced ultrasound) leads to HCC diagnosis in consideration of suspicious nodule of size $(>2 \mathrm{~cm}, 1-$ $2 \mathrm{~cm},<1 \mathrm{~cm})$ and to some extent AFP level $(>200 \mathrm{ng} / \mathrm{ml})$. This approach has two main consequences; first, the biopsy need will be reduced in nodules $>2 \mathrm{~cm}$, second, will detect more nodules $<2 \mathrm{~cm}$ that an exact diagnosis is hard to be achieved by radiological and pathological findings. Dysplastic nodules and early HCC detection will remain difficult $[1,2]$. Although AFP measurement is considered as crucial tool in screening of HCC, some studies reported that it has limited usefulness in differentiating $\mathrm{HCC}$ from benign hepatic disorders. Therefore, mandatory needs to detect highly efficacy novel biomarkers for early HCC detection and its therapeutic monitoring $[\mathbf{3}, \mathbf{4 , 5}$. Many evidences proposed that long noncoding RNAs (lncRNAs) play crucial roles in tumorigenesis and metastasis [6]. LncRNAs was suggested as biomarkers for multiple diseases diagnosis, including cancers. Among many screened lncRNAs, Linc00152 was reported in many cancers such as lung, Kidney, gallbladder and tongue [7]. In this work Linc0015 was chosen as serum biomarker to study its efficacy in differentiating early HCC from liver cirrhosis. 


\section{MATERIALS AND METHODS}

This Cohort (Prospective observational) study was conducted on 60 patients, who were further divided into three groups; 30 patients with cirrhosis and HCC on top (group I), this group was further subdivided into: 15 HCC patients (stage $\mathrm{C}$ and $\mathrm{D}$ ) according to Barcelona-Clinic Liver Cancer (BCLC) staging system (group IA) and 15 HCC patients (stage $\mathrm{A}$ and $\mathrm{B}$ ) according to BCLC staging system (group IB); 15 cirrhotic patients without HCC (group II), lastly 15 healthy subjects with matched age and sex as a control Group (group III). The provisional diagnosis for HCC was based on serum levels of AFP, ultrasonography and Triphasic CT Abdomen. All patients and healthy subjects were evaluated clinically as regards age, sex, symptoms and signs of chronic liver disease, liver size and spleen size. Ten $\mathrm{ml}$ of venous blood was withdrawn from every patient and control subject. The blood samples were thereafter divided into three aliquots; ethylene diamine tetra acetic acid (EDTA) tube, citrated tube and a plain tube, blood was allowed to clot, then centrifuged at $1200 \mathrm{XG}$ for 10 minutes for samples separation, that were kept frozen at $-80^{\circ} \mathrm{C}$ until usage.

Routine investigations were done including; complete blood picture, liver function tests: alanine and aspartate aminotransferase (ALT and AST), serum bilirubin, albumin, alkaline phosphatase, gamma glutamayl transpeptidase (GGT) and prothrombin activity (PA), hepatitis virus markers (HCV antibody \& HBs Abs), AFP was assessed using enzyme-linked immunosorbant assay (ELISA) [8].

Assessment of HCC stage was done according to BCLC staging system [9]. Total RNA isolation of serum samples was done using miRNeasy Mini Kit. (Qiagen) and RNA purity was evaluated using Nano drop followed by complementary DNA (cDNA [7,17]. Program of thermal cycle $(10 \mathrm{~min}$ hold at $25^{\circ} \mathrm{C}$ ), then $120 \mathrm{~min}$ maintained in $37^{\circ} \mathrm{C}$ temperature followed by $5 \mathrm{~min}$ kept in $85^{\circ} \mathrm{C}$, finally decreasing temperature to $4^{\circ} \mathrm{C}$. Each reaction consisted of $10 \mu \mathrm{g}$ RNA extract, $2 \mu \mathrm{l}$ of RT Buffer, $0.8 \mu$ l of denatured protein, $1 \mu$ of reverse transcriptase, $1 \mu$ l RNase Inhibitor, $2 \mu$ RT Random Primers, after which total volume completed to $20 \mu \mathrm{l}$ using nuclease-free water respectively. After which reverse transcription, cDNA was stored at $-20^{\circ} \mathrm{C}$ for latter usage in real time quantitative polymerase chain reaction experiments (RT-qPCR). RT-qPCR was conducted using Thermo Scientific Maxima SYBR Green and specific primers for Linc00152 and Glyceraldehyde 3-phosphate dehydrogenase (GAPDH) as an endogenous control were used (Table1). For each reaction, $12.5 \mu \mathrm{l}$ Maxima SYBR Green qPCR Master Mix (2X), followed by $1 \mu$ Primer (50 pmol), with $1 \mu \mathrm{l}$ reverse primer (50 pmol), $0.1 \mu \mathrm{l}$ ROX Solution, $7.4 \mu \mathrm{l}$ nuclease free water and finally $3 \mu \mathrm{l}$ complementary DNA (c-DNA) were used. Analysis of samples was done in duplicates. RT-qPCR program was as follows: first cycle of $95^{\circ} \mathrm{C}, 10 \mathrm{~min}$; followed by three step cycling: (forty cycles), $95{ }^{\circ} \mathrm{C}$ Denaturation for $15 \mathrm{~s} ; 56^{\circ} \mathrm{C}$ Annealing for Linc 00152 and $65^{\circ} \mathrm{C}$ for GAPDH gene for $30 \mathrm{~s}$ and lastly extension step $72^{\circ} \mathrm{C}$ for 30 s. Melting curve was done for specificity verification and PCR products identification. The variation between sample and control for Linc00152 was calculated with relative quantification method.

\section{Exclusion Criteria:}

Patients with kidney, tongue, lung and gall bladder carcinoma were excluded from this study.

\section{RESULTS}

The serum level of AFP in late HCC group ranged between 4.6 and $1253 \mathrm{ng} / \mathrm{ml}$ with a mean of 297.9 $\pm 389.7 \mathrm{ng} / \mathrm{ml}$, in early HCC group, it varied from 13.5 to $180 \mathrm{ng} / \mathrm{ml}$ with a mean of $48.52 \pm 54.86 / \mathrm{ml}$ and in cirrhosis group, it varied from 4 to $170 \mathrm{ng} / \mathrm{ml}$ with a mean of $35.63 \pm 46.34$. In control group, it ranged from 4 to $5.5 \mathrm{ng} / \mathrm{ml}$ with a mean of $4.67 \pm$ $0.36 \mathrm{ng} / \mathrm{ml}$.

The mean serum AFP showed significant higher level in late $\mathrm{HCC}$, early $\mathrm{HCC}$ and cirrhosis groups compared to the control group ( $p<0.001)$. There was no statistical difference noted in the serum level of AFP between the late and early HCC groups ( $\mathrm{p}=0.148$ ) and between the early HCC and cirrhosis groups $(p=0.174)$. However, significant increase in the serum level of AFP between the late HCC and cirrhosis groups was noted ( $p=0.037)$. (Table 2)

Serum expression of Linc00152 in late HCC patients ranged from 1.39 to 70.59 with a median of 31.27. In early HCC patients, it ranged from 3.9 to 26.75 with a median of 8.43 . While in cirrhotic patients without HCC, it ranged from 0.6 to 12.95 with a median of 4.56. In control group, it varied between 0.14 and 3.29 with a median of 1.12 . 
The mean serum Linc00152 expressed significant higher level in the late HCC, early HCC and cirrhosis groups compared to the control group ( $\mathrm{p}$ $<0.001$ ). Also a statistical difference between the late HCC and cirrhosis groups ( $\mathrm{p}<0.001)$ and between the early $\mathrm{HCC}$ and cirrhosis groups ( $\mathrm{p}$ $=0.002$ ) was observed. However, no statistical difference between the late and early HCC groups was found ( $p<0.098$ ). (Table 3)

For discriminating HCC from liver cirrhosis, serum Linc00152 yielded an AUC of 0.849 (95\% C.I:
$0.734-0.964)$ at a cut-off value of 5.023 and it has $90 \%$ sensitivity and $66.67 \%$ specificity. On the other hand, serum AFP yielded an AUC of 0.686 (95\% C.I: $0.527-0.845$ ) at a cut-off value of 22 and it has $63.33 \%$ sensitivity and $60 \%$ specificity.

Combined together, serum AFP (cut off value $=22$ $\mathrm{ng} / \mathrm{ml}$ ) and serum Linc00152 expression level (cut off value $=5.023 \mathrm{ng} / \mathrm{ml}$ ) had a sensitivity of $86.67 \%$ and a specificity of $80 \%$. (Table 4) (Figure A)

Table (1): Primer sets designed for amplification of cDNA for Linc00152 and GAPDH gene sequences.

\begin{tabular}{|c|c|c|}
\hline Primer & Sequence & Tm $^{\mathbf{c}}\left({ }^{\circ} \mathbf{C}\right)$ \\
\hline LncRNA Linc00152 gene & 5'-CTCCAGCACCTCTACCTGTTG-3' & 56 \\
\hline Sense primer & 5'-GGACAAGGGATTAAGACACACA-3' & 56 \\
\hline Antisense primer & ' & 65 \\
\hline GAPDH gene & 5'-GAAGGTGAAGGTCGGAGTCAAC-3' & 65 \\
\hline Sense primer & 5'-CAGAGTTAAAAGCAGCCCTGGT -3' & \\
\hline Antisense primer &
\end{tabular}

Table (2): Comparison between the studied groups according to AFP.

\begin{tabular}{|c|c|c|c|c|c|c|}
\hline \multirow[b]{2}{*}{ AFP } & \multicolumn{2}{|c|}{ HCC } & \multirow{2}{*}{$\begin{array}{c}\text { Cirrhosis } \\
(\mathbf{n}=15)\end{array}$} & \multirow{2}{*}{$\begin{array}{l}\text { Control } \\
(\mathbf{n}=15)\end{array}$} & \multirow[b]{2}{*}{ H } & \multirow[b]{2}{*}{$\mathbf{P}$} \\
\hline & $\begin{array}{c}\text { Late } \\
(\mathbf{n}=15)\end{array}$ & $\begin{array}{c}\text { Early } \\
(\mathbf{n}=15)\end{array}$ & & & & \\
\hline Min. - Max. & $4.60-1253.0$ & $13.50-180.0$ & $4.50-170.0$ & $4.0-5.30$ & \multirow{3}{*}{$31.889^{*}$} & \multirow{3}{*}{$<0.001^{*}$} \\
\hline Mean \pm SD. & $297.9 \pm 389.7$ & $48.52 \pm 54.86$ & $35.63 \pm 46.34$ & $4.67 \pm 0.36$ & & \\
\hline Median & 40.80 & 26.0 & 20.0 & 4.70 & & \\
\hline pcontrol & $<0.001^{*}$ & $<0.001^{*}$ & $<0.001^{*}$ & & & \\
\hline Significance & \multicolumn{3}{|c|}{$\mathrm{P} 1=0.148, \mathrm{p}_{2}=0.037^{*}, \mathrm{p}_{3}=0.174$} & & & \\
\hline
\end{tabular}

$\mathrm{H}$ : Kruskal Wallis test, Significance between groups was done using Mann Whitney test

MW, $\mathrm{p}$ : MW and $\mathrm{p}$ values for Mann-Whitney test for comparing between the two groups

$\mathrm{P}_{\text {control: }} \mathrm{p}$ value for comparing between control and each other group

P1: $p$ value for comparing between late $\mathrm{HCC}$ and early HCC

P2: $\mathrm{p}$ value for comparing between late $\mathrm{HCC}$ and liver cirrhosis

P3: $p$ value for comparing between early HCC and liver cirrhosis

*: Statistically significant at $\mathrm{p} \leq 0.05$

Table (3): Comparison between the studied groups according to Linc00152.

\begin{tabular}{|c|c|c|c|c|c|c|}
\hline \multirow{2}{*}{$\begin{array}{c}\text { LncRNA } \\
\text { Linc00152 } \\
(2-\Delta \Delta C t)\end{array}$} & \multicolumn{2}{|c|}{ HCC } & \multirow{2}{*}{$\begin{array}{c}\text { Cirrhosis } \\
(\mathbf{n}=15)\end{array}$} & \multirow{2}{*}{$\begin{array}{l}\text { Control } \\
(\mathbf{n}=15)\end{array}$} & \multirow[b]{2}{*}{$\mathbf{H}$} & \multirow[b]{2}{*}{$\mathbf{p}$} \\
\hline & $\begin{array}{c}\text { Late } \\
(\mathbf{n}=15)\end{array}$ & $\begin{array}{c}\text { Early } \\
(n=15)\end{array}$ & & & & \\
\hline Min. - Max. & $3.35-70.59$ & $3.90-26.75$ & $0.60-12.95$ & $0.14-3.29$ & \multirow{3}{*}{$39.230^{*}$} & \multirow{3}{*}{$<0.001^{*}$} \\
\hline Mean \pm SD. & $20.06 \pm 18.05$ & $10.63 \pm 6.74$ & $4.88 \pm 3.15$ & $1.38 \pm 0.96$ & & \\
\hline Median & 15.64 & 8.43 & 4.56 & 1.12 & & \\
\hline pcontrol & $<0.001^{*}$ & $<0.001^{*}$ & $<0.001^{*}$ & & & \\
\hline Significance & \multicolumn{3}{|c|}{$\mathrm{P} 1=0.098, \mathrm{p}_{2}=<0.001^{*}, \mathrm{p}_{3}=0.002^{*}$} & & & \\
\hline
\end{tabular}

H: Kruskal Wallis test, Sig. bet. grps was done using Mann Whitney test

MW, $\mathrm{p}$ : MW and $\mathrm{p}$ values for Mann-Whitney test for comparing between the two groups

$\mathrm{P}_{\text {control: }} \mathrm{p}$ value for comparing between control and each other group

P1: $p$ value for comparing between late $\mathrm{HCC}$ and early HCC

P2: $\mathrm{p}$ value for comparing between late $\mathrm{HCC}$ and liver cirrhosis

P3: $p$ value for comparing between early HCC and liver cirrhosis

*: Statistically significant at $\mathrm{p} \leq 0.05$

Abdelrahman et al., Afro-Egypt J Infect Endem Dis 2020;10(3):264-270

https://aeji.journals.ekb.eg/

http://mis.zu.edu.eg/ajied/home.aspx 
Table (4): Agreement (sensitivity, specificity) for Linc00152 and AFP to diagnose HCC from liver cirrhosis.

\begin{tabular}{|l|c|c|c|c|c|c|c|c|}
\hline Parameter & AUC & P & 95\% C.I & Cut off & Sensitivity & Specificity & PPV & NPV \\
\hline Linc00152 (2- $\mathbf{\Delta} \mathbf{\Delta C t )}$ & 0.849 & $<0.001^{*}$ & $\begin{array}{c}0.734- \\
0.964\end{array}$ & $>\mathbf{5 . 0 2 3}$ & 90.0 & 66.67 & 84.4 & 76.9 \\
\hline AFP & 0.686 & $0.044^{*}$ & $\begin{array}{c}0.527- \\
0.845\end{array}$ & $>\mathbf{2 2}$ & 63.33 & 60.0 & 76.0 & 45.0 \\
\hline Combination & 0.904 & $<0.001^{*}$ & $\begin{array}{c}0.814- \\
0.995\end{array}$ & $\begin{array}{c}>\mathbf{5 . 0 2 3}- \\
>\mathbf{2 2}\end{array}$ & 86.67 & 80.0 & 89.66 & 75.0 \\
\hline
\end{tabular}

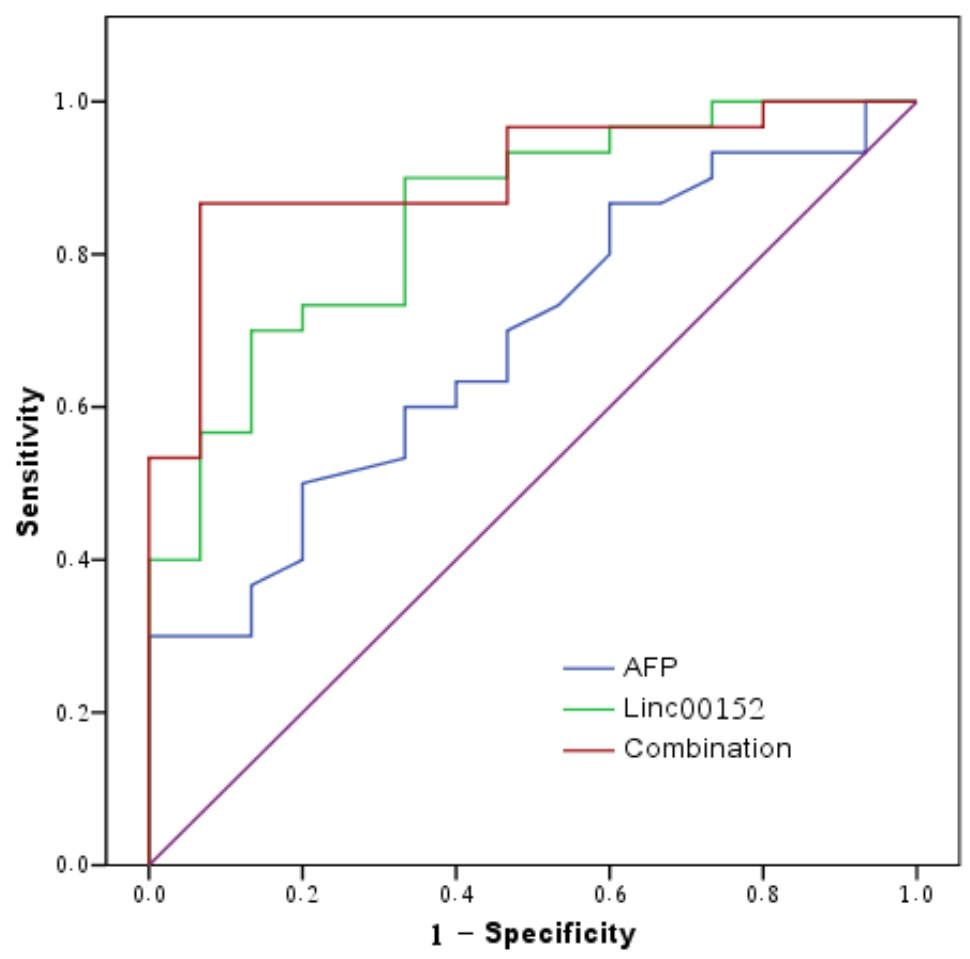

Figure I: ROC curve (sensitivity, specificity) for Linc00152, AFP and combination of both to diagnose $\mathrm{HCC}$ from liver cirrhosis.

\section{DISCUSSION}

HCC is still high, and mortality rates have not improved apparently. This could be due to fact that frequently HCC tumors are detected at stage when no longer curative resection is feasible because of intrahepatic and extra-hepatic metastases. [8] Currently HCC diagnosis relies mostly on radiology and measurement of serum AFP 6-12 month intervals but these isn't adequate for detecting very small $(<2 \mathrm{~cm}) \mathrm{HCC}$. Sensitivity of AFP is low in detection of early-stage HCC. Additionally, raised AFP concentrations were detected in patients with non-malignant changes. So increased demand to find out new highly efficacious biomarkers for early $\mathrm{HCC}$ detection and it's therapeutic monitoring [9].
LncRNAs are non-coding, > 200 nucleotides in length RNA molecules. Biological functions and molecular mechanisms of most lncRNAs remains unclear; Existing evidences demonstrates that these molecules play vital regulatory roles in certain cellular processes, mainly in protein-coding gene expression at epigenetic, transcriptional and posttranscriptional levels $[\mathbf{1 0 , 1 1}]$. Studies demonstrated that IncRNAs were involved in many cancer biological processes such as proliferation, apoptosis, invasion and metastasis $[\mathbf{1 2 , 1 3}$. Additionally, IncRNAs were shown to be upregulated or down-regulated dramatically in tumor tissues in contrast to non-tumor tissues $[\mathbf{1 4 , 1 5}$. lncRNAs can act as oncogenes or tumor-suppressor genes, depending on target genes they regulate [16]. 
Linc00152 attracted attention due to its relationship with malignancies. Moreover, evidences showed that Linc00152 is overexpressed in HCC tissues and cell lines, so it might be involved in pathogenesis of HCC [17,18]. These raised possibility that linc00152 serve as serum marker for malignancy.

In this study, evaluation of possible significance of Linc00152 level as potential biomarker for diagnosis of HCC among Egyptian patients, and determine whether Linc00152 could be used to differentiate HCC from chronic hepatitis, because $80 \%$ to $90 \%$ of HCC patients have established background of chronic hepatitis $\mathrm{B}$ and or $\mathrm{C}$ and liver cirrhosis [19]. Analysis showed significant overexpression of serum Linc00152 among patients with HCC compared to cirrhotic patients without HCC. ROC analyses of serum Linc00152 yielded AUC of 0.849 with $90 \%$ sensitivity and $66.97 \%$ specificity in differentiating patients with HCC from those with cirrhosis. In addition, ROC analyses were assessed for diagnostic performance of serum Linc00152, serum AFP, and their combination to differentiate both late and early HCC from liver cirrhosis. It was observed that Linc00152 alone was superior to AFP in differentiating either late or early HCC from liver cirrhosis. Moreover, combination of both yielded higher AUC. Whether Linc00152 could differentiate between late and early HCC, this study revealed that there was no statistical difference in expression level of serum Linc00152 between studied groups.

These observations was supported by finding of $\mathrm{Li}$ $\mathrm{J}$ et al, who firstly reported that plasma Linc 00152 was up-regulated dramatically in HCC patients, thus they hypothesized that plasma Linc00152 can achieve diagnostic accuracy in diagnosing oncogenesis of HCC and act as novel biomarkers for HCC [20]. They further analyzed expression level of linc00152 in corresponding tissues of same patients and they demonstrated a positive correlation between circulating Linc00152 expression levels and tissues expression levels proving that source of elevated plasma expression is overexpression of linc 00152 in hepatic tissues [20]. Also, there was non-significant difference in plasma linc00152 expression between control group and chronic hepatitis group [20]. Noteworthy this study demonstrated significant increase in serum linc00152 among cirrhotic patients without HCC compared to healthy controls.
Stability of linc00152 in plasma was verified by luo $\mathrm{P}$ et al, who demonstrated that Linc00152 remained stable under harsh conditions such as incubation at room temperature for $0,6,12$, and 24 hours or exposure to repeated freeze-thaw cycles [21]. These results are consistent with previous results in gastric cancer [22]. Stability of circulating IncRNAs may explain by observation that RNase packaged circulating Linc00152 in exosomes to avoid digestion [23]. Another explanation for this stability was that RNase could modify circulating Linc00152 in some ways such as methylation, adenylation, or uridylation, which may make them resistant to decomposition [24].

These results suggest that serum Linc00152 could be a useful HCC biochemical marker. Furthermore, the differentiating power superiority of single measurement of serum Linc00152 compared with AFP was statistically confirmed. The combination differentiating power of serum Linc00152 and AFP was significantly higher than AFP alone, suggesting that measurement of both serum Linc00152 and AFP could have a better differentiating power for $\mathrm{HCC}$ diagnosis than serum Linc00152 or AFP alone.

\section{CONCLUSION}

HCC is clearly accompanied by over expression of serum Linc00152. This study suggested that Linc00152 may be promising diagnostic markers for early HCC, also for cirrhosis detection. In addition, Combination of both AFP and Linc00152 may increase sensitivity \& specificity for suspecting new evolving HCC rather than measuring each separately.

\section{Limitations for study:}

Linc00152 could be important targets for treatment liver cirrhosis. Studies must be conducted on larger groups of HCC patients. Follow up of patients outcome will help identify prognostic value of Linc00152 .

\section{Ethics approval and informed consent:}

The Ethics Review Board of the Faculty of Medicine, Alexandria University, approved this Cohort (Prospective observational) study. Informed consent was obtained from all patients. 
Funding: Non-identified.

\section{Competing interests:}

The authors declare they have neither financial nor non-financial competing interests

\section{REFERENCES}

1. Kim SE, Lee HC, Shim JH, Park HJ, Kim KM, Kim PN, et al. Noninvasive diagnostic criteria of hepatocellular carcinoma among hepatic masses $>2 \mathrm{~cm}$ in a hepatitis B virus-endemic area. Liver Int 2011; 31(10): 1468-76.

2. Yuan Z, Li WT, Ye XD, Zhu HY, Peng WJ. Functional novel magnetic resonance imaging biomarkers in assessing response to hepatocellular carcinoma therapy. Clin Transl Oncol 2013; 16(7): 599-605.

3. Daniele B, Bencivenga A, Megna AS, Tinessa V. $\alpha$-fetoprotein and ultrasonography screening for hepatocellular carcinoma. Gastroenterology 2004; 127(5): S108-12.

4. Gomaa AI, Khan SA, Leen ELS, Waked I, Taylor-Robinson SD. Hepatocellular carcinoma diagnosis. World Journal of Gastroenterology 2009; 15(11): 1301.

5. Trerotoli P, Fransvea E, Angelotti U, Antonaci G, Lupo L, Mazzocca A, et al. Squamous Cellular Carcinoma Antigen (SCCA) tissue expression is inversely correlated to tumor size in HCC. Mol Cancer 2009; 8(1): 29.

6. Liu L, Wen J, Gu X, Wu D, Lu M, Zhao Q. Prognostic role of long non-coding RNA LINC00152 among Chinese cancer patients: a meta-analysis. Oncotarget 2017; 8(54): 9322735.

7. Neumann $\mathrm{O}$, Kesselmeier $\mathrm{M}$, Geffers R, Pellegrino R, Radlwimmer B, Hoffmann K, et al. Analysis of methylome and integrative profiling of human HCCs identify novel protumorigenic factors. Hepatology 2012; 56(5): 1817-27.

8. Zhao J, Greene CM, Gray SG, Lawless MW. Long non-coding RNAs in cancer liver: what we know in 2014. Expert Opin Ther Targets 2014; 18(10): 1207-18.

9. Li H, Li Y, Liu D, Sun H, Liu J. miR-224 is Critical for Celastrol-Induced Inhibition for Migration and Invasion of Hepatocellular Carcinoma Cells. Cell Physiol Biochem 2013; 32(2): 448-58.
10. Marchese FP, Raimondi I, Huarte M. Multidimensional mechanisms of long noncoding RNA function. Genome Biol 2017; 18(1): 206.

11. Iyer MK, Niknafs YS, Malik R, Singhal U, Sahu A, Hosono $\mathrm{Y}$, et al. Landscape of long noncoding RNAs in the human transcriptome. Nat Genet 2015; 47(3): 199-208.

12. Shi D, Zheng H, Zhuo C, Peng J, Li D, Xu Y, et al. Low expression of novel IncRNA RP11$462 \mathrm{C} 24.1$ assumes a biomarker of poor prognosis in colorectal cancer. Med Oncol 2014; 31(7): 31 .

13. Zheng HT, Shi DB, Wang YW, Li XX, Xu Y, Tripathi $\mathrm{P}$, et al. High expression of lncRNA MALAT1 as a biomarker of poor prognosis in colorectal cancer. Int J Clin Exp Pathol 2014; 7(6): 3174-81.

14. Srivastava AK, Singh PK, Rath SK, Dalela D, Goel MM, Bhatt MLB. Diagnostic ability of UCA1 as a biomarker of carcinoma of the urinary bladder. Tumour Biol 2014; 35(11): 11435-42.

15. Zhang X, Gejman R, Mahta A, Zhong Y, Rice KA, Zhou Y, et al. Maternally Expressed Gene 3 as an Imprinted Noncoding RNA Gene, is Associated with Meningioma Pathogenesis and Progression. Cancer Res 2010; 70(6): 2350-8.

16. Siddiqi S, Matushansky I. Piwis and piwiinteracting RNAs in epigenetics of cancer. $J$ Cell Biochem 2012; 113(2): 373-80.

17. Ji J, Tang J, Deng L, Xie Y, Jiang R, Li G, et al. LINC00152 promotes proliferation among hepatocellular carcinoma by targeting EpCAM via the mTOR signaling pathway. Oncotarget 2015; 6(40): 42813-24.

18. Ma P, Wang H, Sun J, Liu H, Zheng C, Zhou X, et al. LINC00152 promotes progression of cell cycle in hepatocellular carcinoma via miR193a/b-3p/CCND1 axis. Cell Cycle 2018; 17(8): 974-84.

19. Perz JF, Armstrong GL, Farrington LA, Hutin YJF, Bell BP. Contributions of hepatitis B virus and hepatitis $\mathrm{C}$ virus infections to cirrhosis and primary liver cancer worldwide. J Hepatol 2006; 45(4): 529-38.

20. Li J, Wang X, Tang J, Jiang R, Zhang W, Ji J, et al. HULC and Linc00152 Act as Novel Biomarkers in Diagnosis predication of Hepatocellular Carcinoma. Cell Physiol Biochem 2015; 37(2): 687-96. 
21. Li N, Feng XB, Tan Q, Luo P, Jing W, Zhu M, et al. Identification of Circulating Long Noncoding RNA Linc00152 as a Novel Biomarker for Non-Small-Cell Lung Cancer Diagnosis and Monitering. Disease markers 2017; 2017:7439698.

22. Jin C, Shi W, Wang F, Shen X, Qi J, Cong H, et al. Long non-coding RNA HULC as a novel serum biomarker for gastric cancer diagnosis and prognosis prediction. Oncotarget 2016; 7(32): 51763-72.

23. Li Q, Shao Y, Zhang X, Zheng T, Miao M, Qin $\mathrm{L}$, et al. Plasma long noncoding RNA protected by exosomes as potential stable biomarker of gastric cancer. Tumor Biol 2014; 36(3): 2007-12.

24. Redova M, Sana J, Slaby O. Circulating miRNAs as new blood-based biomarkers for solid cancers. Future Oncol 2013; 9(3): 387-402. 